\title{
Rotational Viscometry of a Zinc Phosphate and a Zinc Polyacrylate Cement
}

\author{
S. Vermilyea, J. M. Powers, and R. G. Craig \\ School of Dentistry, The University of Michigan, Ann Arbor, Michigan 48109, USA
}

The rheological properties of a zinc phosphate and a zinc polyacrylate cement were investigated using a rotational viscometer. The effects of time, temperature, shear rate, and spindle geometry on the measured viscosities were evaluated. Results indicated that both cements exhibited Nevtonian behavior.

\section{J Dent Res 56(7): 762-767, July, 1977.}

A key step in the construction of a successful fixed prosthetic appliance is the cementation of the finished restoration. All of the skill and care involved in the fabrication of the appliances are wasted if the ccmentation procedure is accomplished haphazardly. One of the factors affecting cementation is the rheological (viscous) properties of the cementing medium.

A well-known method for evaluation of the flow properties of cement is included in ADA Specification No. $8{ }^{1}$ In this consistency test, a standard volume of cement is compressed between two glass plates and allowed to flow for ten minutes. The diameter of the cement disk is used as an indication of the consistency

Received for publication April 30, 1976.

Accepted for publication September 28, 1976.

S. Vermilyea gratefully acknowledges the U. S. Army Dental Corps for financial support of his graduate training.

This investigation was presented in part at the 54th Annual Meeting of the International Association for Dental Research in Miami Beach, Florida, March 1976. This investigation was based on a thesis submitted in partial fulfilment of the requirements for the MS degree in the Horace $\mathbf{H}$. Rackham School of Graduate Studies at The University of Michigan, 1976.

* Modern Tenacin, powder-P74342, liquid-L74227, L. D. Caulk Company, Milford, De 19963.

$\dagger$ Durelon, powder-PA31239 and PA157A50, liquid -LA16939 and LA14210, Premier Dental Products Company, Philadelphia, Pa. 19107.

RTV Rheolog with $1 / 4 \times$ Spring, Brookfield Engineering Corporation, Stoughton, Ma. 02072.

\& Spindle \#7, Brookfield Engineering Corporation, Stoughton, Ma. 02072

I Brookfield Engineering Corporation, Stoughton, Ma. 02072.

\# Viscosity standard (100500 cp), Brookfield Engineering Corporation, Stoughton, Ma. 02072.

** N190000 (923,100 cp) standard, Cannon Instrument Company, State College, $\mathrm{Pa}$.

it Foxboro pneumatic recorder, Model 5310-E, Foxboro oCrporation, Foxboro, Ma. 02035. of the material. This test yiclds no information regarding the viscous changes occurring during the ten-minute period, nor is the effect of load variation evaluated.

Several authors have investigated the rheological properties of cements. Houston and Miller, ${ }^{2}$ in 1968, and Plant, Jones, and Wilson, ${ }^{3}$ in 1972 , used oscillating rheometers to measure working times of dental cements. Combe, ${ }^{4}$ in 1975 , studied the rheological properties of several polycarboxylate cements as a function of shear rate using an extrusion viscometer.

The present investigation was undertaken to evaluate the flow properties of two dental cements as a function of time, temperature, and shear rate using a rotational viscometer. In addition, the effect of spindle geometry on the viscosity of one material was evaluated.

\section{Materials and Methods}

Two dental cements, a zinc phosphate material* (A) and a zinc polycarboxylate materialt (B) were chosen for this study.

A rotational viscometer $\ddagger$ was used to evaluate the flow properties of these materials. A cylindrical rod $\$$ (diameter $3.17 \mathrm{~mm}$ ) or a t-bar spindlef (crosspiece length $6.50 \mathrm{~mm}$ ) was attached to the driving mechanism of the viscometer through a calibrated spring. Rotation of the spindle in the test material applies a torque to the spring which may be converted directly to viscosity in centipoise (cp) by calibrating the recording device with Newtonian liquids, $\# * *$ of known viscosity. A pneumatic recordert was employed to provide a record of the rheologic behavior of the test materials. The rotational speeds of the spindles were varied from 1.0 to 20 revolutions per minute $(\mathrm{rpm})$. The viscosity in centipoise was recorded continuously from 45 seconds following the termination of spatulation until the viscosity of the mix exceeded the range of the recorder.

The viscosity of most materials is extremely sensitive to temperature variation and 
for this reason temperature control was maintained at $\pm 0.5 \mathrm{C}$ by a constant temperature chambcr and water bath. Mixing was accomplished in the chamber and the samples were contained in a glass vial with an inside diameter of $10.4 \mathrm{~mm}$ which was suspended in the water bath during the time of measurement to insure adequate temperature control. T'emperature effects on each material were evaluated at 25 , 20 , and $18 \mathrm{C}$.

All materials were mixed according to manufacturers' directions to provide a volume of $1 \mathrm{~cm}^{3}$. Five replications were made with each material at each shear rate and temperature. All data were analyzed by analysis of variance ${ }^{5}$ and means compared using a Scheffe interval ${ }^{6}$ at the $95 \%$ level of confidence.

\section{Results}

The viscosity of both materials increased markedly with time. The mean values of viscosity were statistically different at the $95 \%$ level of confidence with a Scheffe interval of 4,970 cp. Figure 1 demonstrates the changes in viscosity of both materials with time at $25 \mathrm{G}$ and $5 \mathrm{rpm}$. The mean value of initial viscosity with the standard deviation in parentheses of $A$ was $94,700(2,500) \mathrm{cp}$ and that of $\mathrm{B}$ was 109,800 $(2,700) \mathrm{cp}$. At two minutes after the mixing the viscosity of $\mathrm{A}$ had increased about 10 times to $953,000(12,000) \mathrm{cp}$ and that of $B$ about 4 times to $480,000(8,000) \mathrm{cp}$.

The effect of spindle geometry on the viscosity of $\mathrm{A}$ is seen in Figure 2. The values shown were obtained at $10 \mathrm{rpm}$ and $18 \mathrm{C}$. The $\mathrm{t}$-bar resulted in mean values of initial viscosity about $11 \%$ lower than those obtained using the cylindrical spindle. The Scheffe interval at the $95 \%$ level of confidence was $1,900 \mathrm{cp}$. As the time from the termination of mixing increased, the differences in viscosity determined with the $\mathrm{t}$-bar and cylindical spindle increased to about $25 \%$.

Temperature effects on the initial viscosity (45 seconds after mixing) of each material at $5 \mathrm{rpm}$ are seen in Figure 3. Material $\mathrm{A}$ demonstrated a 54\% drop in initial viscosity with a $7 \mathrm{C}$ decrease in temperature while material $\mathrm{B}$ showed only an $8 \%$ decrease over the same temperature range.

The mean values of initial viscosities with standard deviations in parentheses at

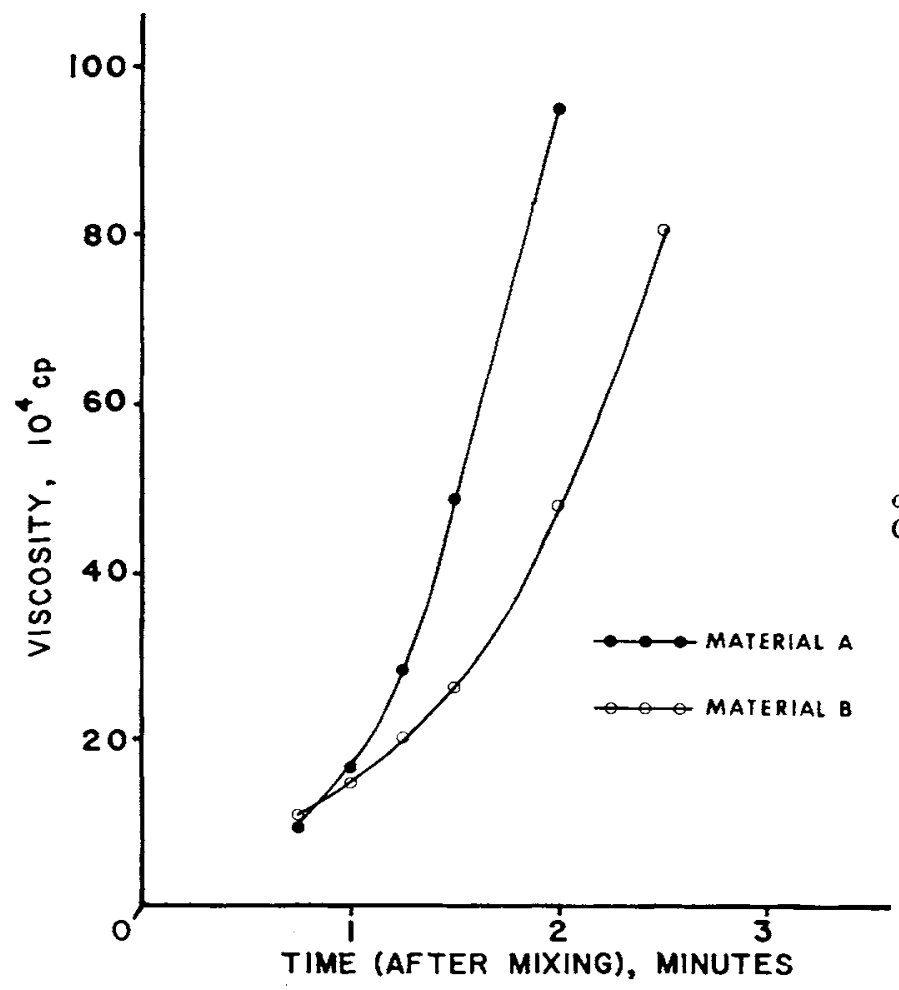

Fig 1.-Change in viscosity of each material with time at 25 $\mathrm{C}$ and $5 \mathrm{rpm}$. 
FIG 2.- Change in viscosity of $A$ with time using different spindles at $18 \mathrm{C}$ and $10 \mathrm{rpm}$.

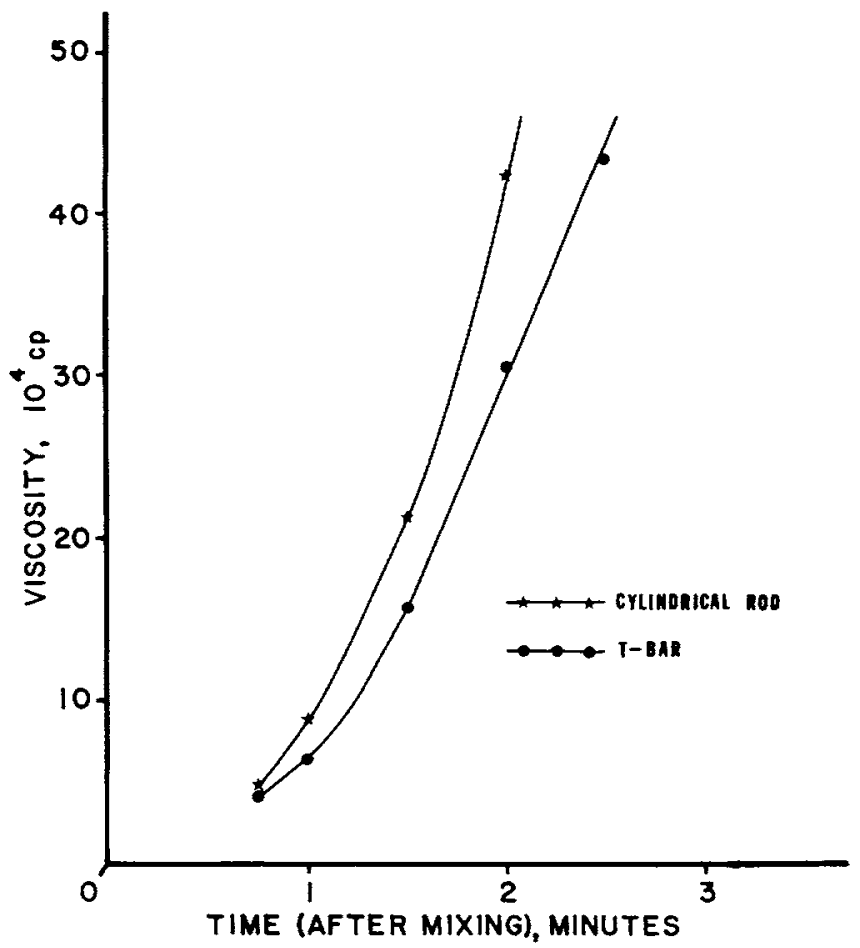

25,20 , and $18 \mathrm{C}$ were $94,700(2,500), 59,300$ $(4,000)$, and $43,200(3,000) \mathrm{cp}$ for $\mathrm{A}$ and $109,800(2,700), 108,300(2,200)$, and 101,000 (4,000) for B, respectively. The Scheffe intervals were $2,900 \mathrm{cp}$ for $\mathrm{A}$ and $3,000 \mathrm{cp}$ for $B$. At two minutes following the termination of mixing (Fig 4), material A demonstrated a $52 \%$ difference in viscosity over the temperature range while $\mathrm{B}$ had a $38 \%$ difference in viscosity from 25 to $18 \mathrm{C}$. The viscosities at 25,20 , and $18 \mathrm{C}$ at two minutes after mixing were 953,000 $(12,000), 515,000(11,000)$, and 455,600 $(16,000) \mathrm{cp}$ for $\mathrm{A}$ with a Scheffe interval of $16,300 \mathrm{cp}$ and the viscosities for $\mathrm{B}$ were 480,000 $(8,000), 358,500(14,000)$, and $295,400(6,300)$ $\mathrm{cp}$ with a Scheffe interval of $14,200 \mathrm{cp}$, respectively.

Figure 5 demonstrates the effect of rota-

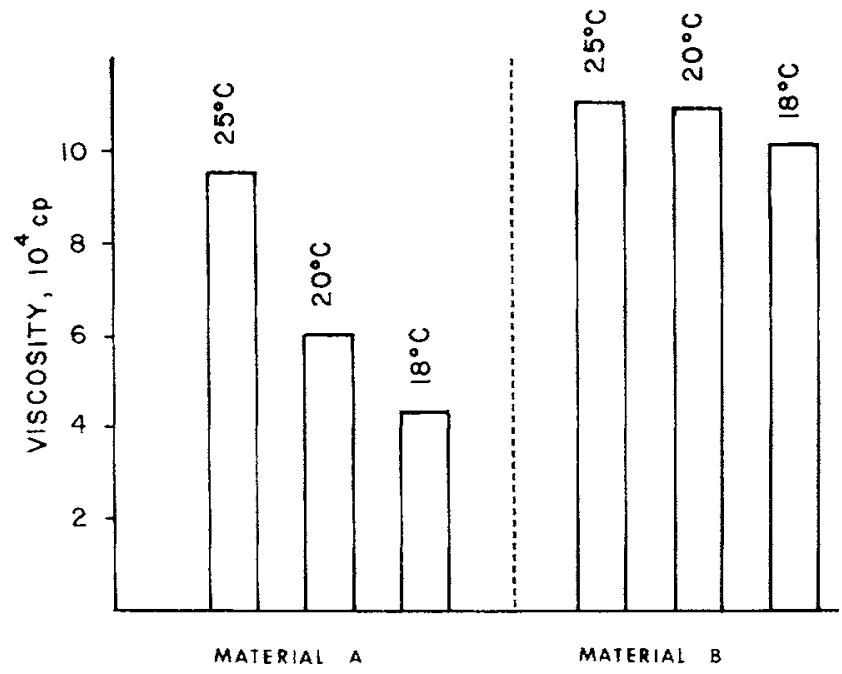

Fig 3.-Change in initial viscosity of each material with temperature at $5 \mathrm{rpm}$. 
FIG 4.-Change in viscosity of each material with temperature at $5 \mathrm{rpm}$ and two minutes after mixing.

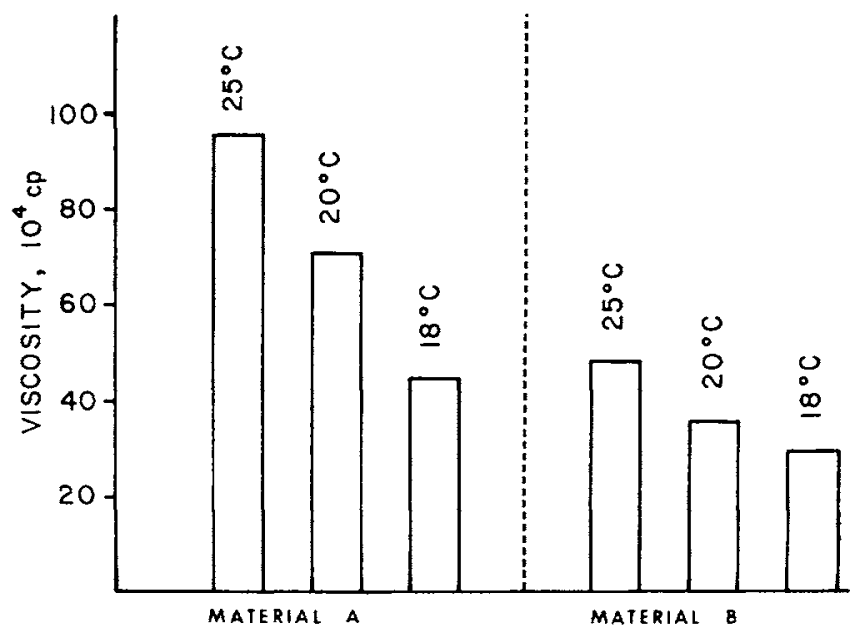

tional speed on the initial viscosity of the two materials at $25 \mathrm{C}$. These graphs are somewhat difficult to interpret in terms of fundamental rheological quantities. Inspection suggests that material A showed a slight decrease in viscosity with increased rotational speed while $B$ indicated little change in viscosity over the range of rotational speeds.

\section{Discussion}

The rapid increase in the viscosity of both cements with increased time from the termination of mixing results from the setting reaction of both materials and would continue until the material was completely set. The tenfold increase in the viscosity of $A$ and the fourfold increase in the viscosity of $B$ at two min- utes after the mixing suggest a slightly longer working time available with the zinc polyacrylate cement $(\mathrm{B})$. The manufacturers indicate a 1.5-minute working time for the zinc phosphate cement (A) and two minutes for the zinc polyacrylate cement (B). Inspection of Figure 1 reveals that the viscosity of $A$ at 1.5 minutes after mixing $(488,000 \mathrm{cp})$ is only slightly different from that of $\mathrm{B}$ at two minutes after mixing $(480,000 \mathrm{cp})$. These data may suggest a range of viscosity for use in a viscometric method of establishing working times for dental cements in further studies.

The differences in viscosities of material $\mathrm{A}$ with the cylindrical rod and t-bar spindles may be a result of interference of the formation of the matrix in the set material. Since the zinc phosphate cement consists of a matrix of amor-

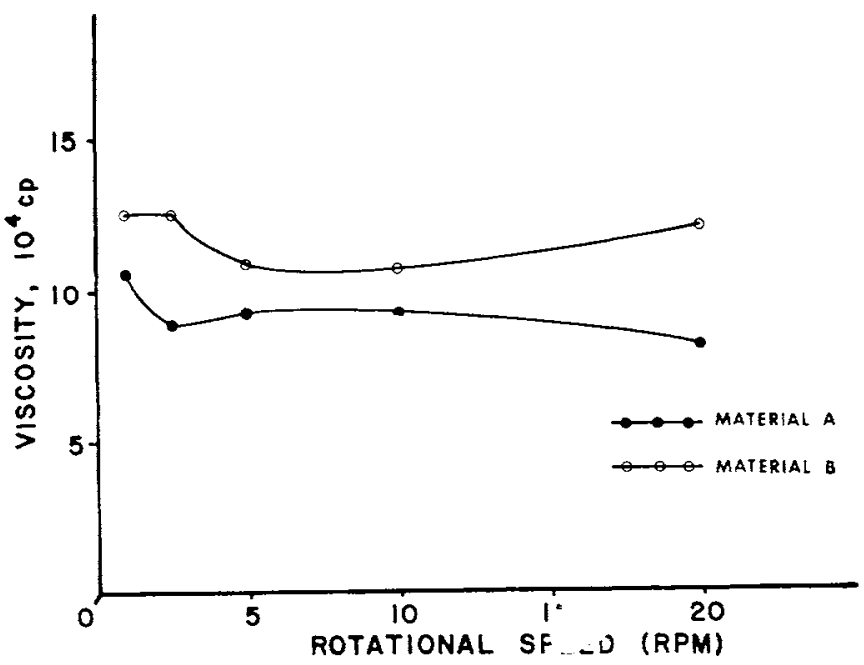

FIG 5.-Change in initial viscosity of each material with rotational speed. 
phous zinc phosphate surrounding the unreacted zinc oxide particles, ${ }^{7}$ the continued mixing motion of the rotating t-bar spindle may inhibit matrix formation and result in lower viscosities than those obtained with the cylindrical rod.

The magnitude of the decrease in initial viscosity from $25 \mathrm{C}$ to $18 \mathrm{C}(54 \%)$ for the zinc phosphate cement (A) indicates the retardation of the setting reaction in a cool environment. The minimal decrease in initial viscosity of the zinc polyacrylate cement (B) over the temperaature range suggests that the setting reaction has not progressed sufficiently to exhibit dramatic temperature effects. At two minutes following mixing, however, material $\mathrm{B}$ demonstrated a $38 \%$ decrease in viscosity over the temperature range, indicating a significant temperature effect on the setting reaction.

In order to clarify the interpretation of the effect of rotational speed on the viscosity of both materials (Fig 5), a mathematical model was applied to the data. The interpretation of viscometric data may be simplified if the test ma-. terial obeys a power law in the form of

$$
\mathrm{S}=\mathrm{k}(\gamma)^{\mathrm{n}}
$$

where $\mathrm{S}$ is the shear stress in dynes $/ \mathrm{cm}^{2}, \gamma$ the shear rate in reciprocal seconds $\left(\mathrm{sec}^{-1}\right)$, and $n$ and $k$ are constants. ${ }^{8}$

In addition, the shear stress may be calculated as a function of the torque $(m)$ in dyne- $\mathrm{cm}$ measured by the viscometer, the radius of the spindle $(R)$ in $m$, and the depth of immersion of the spindle $(h)$ in $\mathrm{cm}$ by the equation, ${ }^{8}$

$$
\mathrm{S}=\frac{\mathrm{m}}{2 \pi \mathrm{R}^{2} \mathrm{~h}}
$$

It can be shown mathematically that the slope of a log-log plot of the angular velocity of the spindle ( $\Omega$ ) versus the shear stress (S) is a straight line whose slope is the reciprocal of " $n$ ", the power law exponent (equation 1).s This power law is not only convenient because of its simplicity, but provides a simple test for the classification of rheologic behavior. If in equals one the substance is classified as Newtonian; if $\mathrm{n}$ is less than one the material is pseudoplastic, and if $n$ is greater than one the material is dilatant.

The results of a regression analysis of a $\log -\log$ plot of $\Omega$ versus $S$ is shown in Figure 6. The analysis resulted in a computed value of $\mathrm{F}$ of 3,270 for the polycarboxylate material and 2930 for the zinc phosphate cement. These values of $F$ are much greater than $F .95 ; 1,23=$ 4.28 and suggest that a linear regression line is appropriate for these data. The $\mathrm{n}$ value for material A was 0.967 and that for $\mathrm{B}$ was 1.002 . These values of $n$ were not statistically different from 1.000 at the $95 \%$ level of confidence. Thus, both materials appear to exhibit Newtonian behavior at this time and temperature.

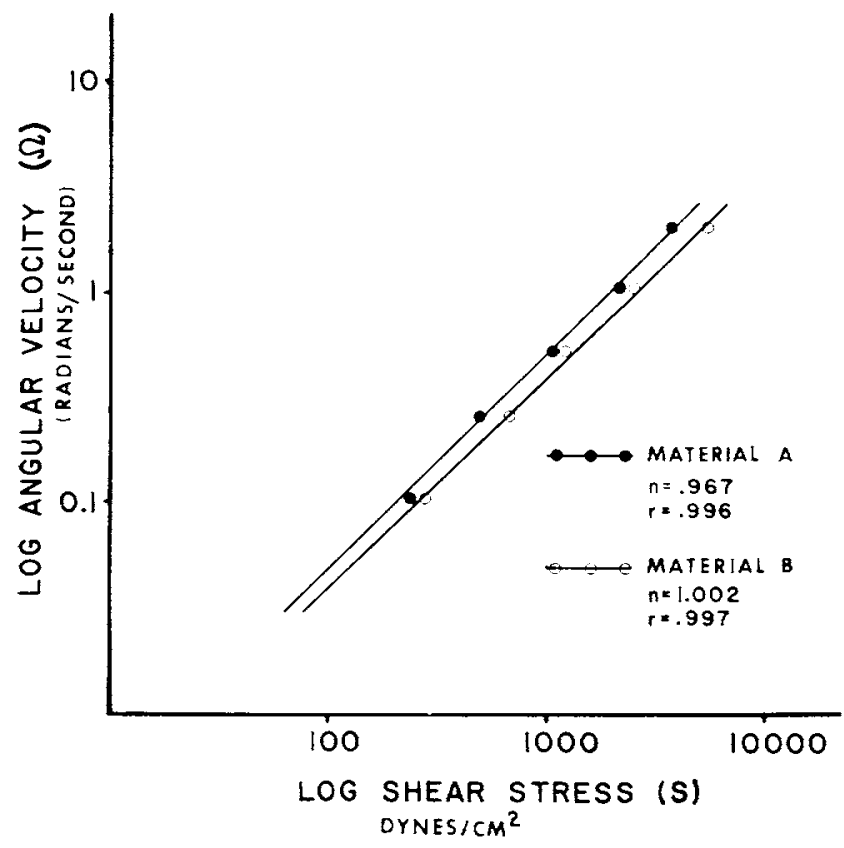

FIG 6.- $\log \Omega$ versus $\log S$ for each material at 45 seconds after mixing and $25 \mathrm{C}$. 


\section{Conclusions}

A rotational viscometer was used to evaluate the effects of time, temperature, shear rate, and spindle geometry on the viscosities of a zinc phosphate and a zinc polyacrylate dental cement.

A power law equation adequately described the flow curves of both materials. In each instance the exponent, " $\mathrm{n}$ " of the power law was about one at $25 \mathrm{C}$ and 45 seconds after mixing, indicating Newtonian behavior.

The initial viscosity of both materials was affected more by temperature than by shear rate; however, the temperature effect was greater for the zinc phosphate cement than for the zinc polyacrylate cement.

The geometry of the spindles produced significant differences in the measured viscosities. The t-bar spindle resulted in values of viscosity about $11 \%$ lower than values obtained using the rod for the zinc phosphate cement.

The viscosity of both materials increased markedly with time. The viscosity of zinc phosphate cement increased at a faster rate than did that of the zinc polyacrylate cement at times measured from completion of mixing.

The use of colder mixing environments dramatically reduced the viscosity of these materials at any given time point.

\section{References}

1. American Dental Association: Guide to Dental Materials and Devices, 6th ed., Chicago, 1974-75, 297 pp.

2. Houston, W.J., and Miller, M.W.: Cements for Orthodontic Use, Dent Practit 19:104-109, 1968.

3. Plant, C.G.; Jones, I.H.; and Wilson, H.J.: Setting Characteristics of Lining and Cementing Materials, Brit Dent J 133:2124, 1972.

4. Сомвe, E.C.: The Rheology of Zinc Polycarboxylate Cements. Microfilmed paper No. 140 [Delivered at] the Annual Meeting of the American Association for Dental Research, Dental Materials Group, New York, April 5-8, 1975.

5. University of Michigan, Statistical Research Laboratory: A Manual of Elementary Statistics Using MIDAS, Ann Arbor, Statistical Research Laboratory, 1973, 301 pp.

6. Guenther, W.C.: Analysis of Variance, Englewood Cliffs, NJ, Prentice-Hall, Inc., 1964, $141 \mathrm{pp}$.

7. Servais, G.E., and Cartz, L.: Structure of Zinc Phosphate Dental Cement. J Dent Res 50:613-620, 1971.

8. VAN WAZER, J.R., et al: Viscosity and Flow Measurements, New York, John Wiley and Sons, $1960,780 \mathrm{pp}$. 